University of Nebraska - Lincoln

DigitalCommons@University of Nebraska - Lincoln

USDA Wildlife Services - Staff Publications

U.S. Department of Agriculture: Animal and Plant Health Inspection Service

6-25-2007

\title{
Fence-Line Contact Between Wild and Farmed Cervids in Colorado: Potential for Disease Transmission
}

\author{
Kurt C. VerCauteren \\ USDA-APHIS-Wildlife Services, kurt.c.vercauteren@usda.gov \\ Michael J. Lavelle \\ USDA/APHIS/WS National Wildlife Research Center, michael.j.lavelle@aphis.usda.gov \\ Nathan W. Seward \\ United States Department of Agriculture, Animal and Plant Health Inspection Service, Wildlife Services, \\ National Wildlife Research Center \\ Justin W. Fischer \\ USDA/APHIS/WS National Wildlife Research Center, Justin.w.fischer@aphis.usda.gov \\ Gregory E. Phillips \\ United States Department of Agriculture, Animal and Plant Health Inspection Service, Wildlife Services, \\ National Wildlife Research Center
}

Follow this and additional works at: https://digitalcommons.unl.edu/icwdm_usdanwrc

Part of the Environmental Sciences Commons

VerCauteren, Kurt C.; Lavelle, Michael J.; Seward, Nathan W.; Fischer, Justin W.; and Phillips, Gregory E., "Fence-Line Contact Between Wild and Farmed Cervids in Colorado: Potential for Disease Transmission" (2007). USDA Wildlife Services - Staff Publications. 722.

https://digitalcommons.unl.edu/icwdm_usdanwrc/722

This Article is brought to you for free and open access by the U.S. Department of Agriculture: Animal and Plant Health Inspection Service at DigitalCommons@University of Nebraska - Lincoln. It has been accepted for inclusion in USDA Wildlife Services - Staff Publications by an authorized administrator of DigitalCommons@University of Nebraska - Lincoln. 


\title{
Fence-Line Contact Between Wild and Farmed Cervids in Colorado: Potential for Disease Transmission
}

\author{
KURT C. VERCAUTEREN, ${ }^{\mathbf{1}}$ United States Department of Agriculture, Animal and Plant Health Inspection Service, Wildlife Services, National Wildife \\ Research Center, 4101 LaPorte Avenue, Fort Collins, CO 80521, USA \\ MICHAEL J. LAVELLE, United States Department of Agriculture, Animal and Plant Health Inspection Service, Wildlife Services, National Wildlife \\ Research Center, 4101 LaPorte Avenue, Fort Collins, CO 80521, USA \\ NATHAN W. SEWARD, United States Department of Agriculture, Animal and Plant Health Inspection Service, Wildlife Services, National Wildlife \\ Research Center, 4101 LaPorte Avenue, Fort Collins, CO 80521, USA \\ JUSTIN W. FISCHER, United States Department of Agriculture, Animal and Plant Health Inspection Service, Wildife Services, National Wildlife \\ Research Center, 4101 LaPorte Avenue, Fort Collins, CO 80521, USA \\ GREGORY E. PHILLIPS, United States Department of Agriculture, Animal and Plant Health Inspection Service, Wildlife Services, National Wildlife \\ Research Center, 4101 LaPorte Avenue, Fort Collins, CO 80521, USA
}

\begin{abstract}
Direct and indirect contact between wild and farmed cervids along perimeter fences may play a role in transmission of diseases like chronic wasting disease (CWD), but no studies have quantified such interactions. At 9 high-fenced commercial elk (Cervus elaphus) farms in Colorado, USA, during October 2003 to January 2005, we used animal-activated video to estimate rates of fence-line use by wild cervids, rates of direct contact between farmed and wild cervids, and probability of direct contact when wild cervids were present. We recorded 8-foldmore wild elk per unit time than mule deer (Odocoileus hemionus) at fence lines. Depending on site, we recorded 0.66 to 46.90 wild elk per 1,000 hours of camera monitoring. We documented 77 interactions between wild and farmed elk involving naso-oral contact and no contact between wild mule deer and farmed elk. Rate of direct contact ranged from 0.00 to 1.92 direct contacts per 1,000 hours of camera monitoring among sites. Given recorded presence of wild elk, estimated probability of observing direct contact during a 2-minute video recording ranged from 0.00 to 0.11 among sites. Risk of direct contact was about 3.5 times greater for single woven-wire fence compared with offset electric fence attached to a single woven-wire fence. We observed no direct contact through double woven-wire fences. Because little is currently known about infection rates associated with infection mechanisms, we cannot infer a level of CWD infection risk from our results, but some form of double fencing should reduce potential for direct and indirect transmission of disease into or out of elk farms. (JOURNAL OF WILDLIFE MANAGEMENT 71(5):1594-1602; 2007)
\end{abstract}

DOI: $10.2193 / 2006-178$

KEY WORDS animal-activated cameras, cervid, Cervus elaphus, chronic wasting disease, Colorado, disease transmission, elk, fence-line contact, mule deer, Odocoileus hemionus.

Potential for disease transmission at high-fenced commercial elk (Cervus elaphus) farms (hereafter farms) between wild and farmed cervids is a matter of concern for both wildlife managers and elk farmers (Demarais et al. 2002). Historically, wildlife agencies have emphasized risks of farmed cervids transmitting disease to wild animals (Lanka and Guenzel 1991, Miller and Thorne 1993, Wheaton et al. 1993). However, disease transmission can occur in both directions, and diseases that persist in wild populations may threaten traditional and alternative livestock operations (Buck 2002, Coon et al. 2002, Diez et al. 2002).

Chronic wasting disease (CWD; Williams and Young 1980, 1982) is a transmissible spongiform encephalopathy (TSE) of cervids and is endemic in many areas of North America (Miller et al. 2000, Williams et al. 2002, Williams 2005). Abnormal prion isoforms are generally thought to be the infectious agents of TSE diseases (Prusiner 1998). Although specific mechanisms of CWD prion transmission have not been identified, CWD is infectious and contagious (Williams et al. 2002, Miller and Williams 2004), and horizontal animal-to-animal transmission is more likely than maternal transmission (Miller et al. 2000, Miller and Williams 2003). Miller et al. (2004) demonstrated that

\footnotetext{
${ }^{1}$ E-mail: Kurt.C.VerCauteren@aphis.usda.gov
}

uninfected mule deer (Odocoileus hemionus) contracted CWD when kept with infected mule deer. They also documented that mule deer contracted CWD when kept in pens that previously contained infected individuals. Infective CWD prions appear to persist in the environment $\geq 2$ years (Miller et al. 2004).

Oral exposure is considered the most likely route of CWD infection (Miller et al. 1998, Sigurdson et al. 1999, Williams 2003) and TSE infection in general (Williams 2005). Experimental oral exposure of mule deer and elk to CWD-infected brain resulted in spongiform lesions in brain tissues of both species (Williams and Miller 2002). Similarly, oral exposure to saliva from CWD-infected white-tailed deer (Odocoileus virginianus) transmitted the disease (Mathiason et al. 2006). Prions may also be transmitted through blood, urine, and feces (Sigurdson et al. 1999, Spraker et al. 2002, Williams and Miller 2002, Mathiason et al. 2006).

If CWD exists in cervid populations either inside or outside of farms, direct and indirect transmission might occur along fences. Concentrated cervid activity may occur along perimeter fences because animals within farms may attract wild conspecifics and fence lines tend to become travel routes for animals on both sides. Direct and indirect contact, potentially involving transfer of saliva, is possible at 
farms with only a single perimeter fence. Mesh size of typical woven-wire fences allows penetration by the entire rostrum of deer and elk. Further, cervid activity concentrated along fences may lead to accumulation of CWD prions in adjacent soil and vegetation. Wire fences would provide no barrier to wind-borne or water-borne infectious materials, and potentially contaminated vegetation might be available for consumption through fences. Because CWD in farmed cervids has been implicated in contemporaneous outbreaks of CWD in wild populations (Williams et al. 2002), potential for transmission along fences warrants further study.

We hypothesize that risk of CWD transmission between wild and farmed cervids is positively associated with levels of cervid activity along fences. Although it is currently not possible to test this hypothesis or estimate strength of association, we conducted an exploratory observational study to examine potential for direct and indirect transmission of CWD between wild and farmed cervids at fence lines. Our objectives were to 1) quantify indices of wild cervid activity near fence lines at 9 elk farms in Colorado, USA, 2) document behaviors and contacts between wild and farmed cervids, 3) quantify indices of direct contact through fences, and 4) estimate probabilities of direct contact with farmed elk, given presence of wild cervids at fences.

\section{STUDY AREA}

We worked on 9 privately owned elk farms in Colorado (locations and ownership not provided per United States Department of Agriculture policy). Study sites (enclosures at farms) varied in size, fence type, and habitat type. All study sites were located in areas with suitable habitat for wild elk and mule deer. We verified likely presence of wild elk and mule deer near study sites using digital species-activity maps (Colorado Division of Wildlife 2004). For sites outside delineated activity areas, we estimated shortest distances from approximate boundaries using ArcView Geographic Information System. Unless otherwise noted in site descriptions, sites were located within the overall range of each species, within winter and summer range of mule deer, and within winter range of elk.

\section{Site 1}

The fenced area was 276 ha with perimeter length of 8,894 $\mathrm{m}$. Eighty-three percent of the perimeter consisted of one woven-wire fence ( $2.4 \mathrm{~m}$ high) plus a 3-strand offset electric fence $(0.6 \mathrm{~m}$ inside the woven-wire fence; top strand energized, $1.2 \mathrm{~m}$ above ground level; middle strand grounded, $0.6 \mathrm{~m} \mathrm{ht}$; lower strand energized, $0.3 \mathrm{~m} \mathrm{ht}$ ). Seventeen percent of the perimeter fence consisted of 2 woven-wire fences ( $2.4 \mathrm{~m}$ high, separated by approx. $4 \mathrm{~m}$ ). Elevation averaged $2,620 \mathrm{~m}$, with the surrounding vegetation characterized by aspen (Populus tremuloides), big sagebrush (Artemisia tridentata), and lodgepole pine (Pinus contorta). Site 1 was located within the summer range of elk and approximately $4 \mathrm{~km}$ outside of mule deer winter range.

\section{Site 2}

The fenced area was 9 ha with a perimeter length of 1,503 $\mathrm{m}$. Seventy-eight percent of the perimeter consisted of one woven-wire fence $(2.4 \mathrm{~m}$ high), and $22 \%$ consisted of 2 woven-wire fences $(2.4 \mathrm{~m}$ high, separated by approx. $1 \mathrm{~m})$. Elevation averaged $1,930 \mathrm{~m}$, with surrounding vegetation characterized by dryland crops, big sagebrush, and mixed oak (Quercus spp.).

\section{Site 3}

The fenced area was 33 ha with a perimeter length of 2,509 $\mathrm{m}$. Seventy-eight percent of the perimeter consisted of one woven-wire fence $(2.4 \mathrm{~m}$ high), and $22 \%$ consisted of 2 woven-wire fences $(2.4 \mathrm{~m}$ high, separated by $\geq 4 \mathrm{~m}$ ). Elevation averaged 2,010 $\mathrm{m}$ with surrounding vegetation characterized by dryland crops and big sagebrush.

\section{Site 4}

The fenced area was 43 ha with a perimeter length of 3,273 $\mathrm{m}$. The entire perimeter consisted of one woven-wire fence (2.4 $\mathrm{m}$ high). Elevation averaged 2,130 $\mathrm{m}$ with surrounding vegetation characterized by aspen and mixed oak. Site 4 was located approximately $2 \mathrm{~km}$ and $8 \mathrm{~km}$ outside the winter range for elk and mule deer, respectively.

\section{Site 5}

The fenced area was 7 ha with a perimeter length of 1,246 $\mathrm{m}$. Four percent of the perimeter consisted of one wovenwire fence $(2.4 \mathrm{~m}$ high) plus a 3-strand offset electric fence (0.6 $\mathrm{m}$ outside the woven-wire fence; top strand energized, $1.1 \mathrm{~m}$ above ground level; middle strand grounded, 0.6-m ht; lower strand energized, $0.3-\mathrm{m} \mathrm{ht})$. Ninety-six percent of the perimeter consisted of 2 woven-wire fences $(2.4 \mathrm{~m}$ high, separated by approx. $2 \mathrm{~m}$ ). Elevation averaged $1,800 \mathrm{~m}$ with surrounding vegetation characterized by ponderosa pine (Pinus ponderosa), juniper (Juniperus spp.), and dryland crops. Site 5 was approximately $2 \mathrm{~km}$ and $3 \mathrm{~km}$ outside overall and winter ranges of elk, respectively.

\section{Site 6}

The fenced area was 21 ha with a perimeter length of 2,635 $\mathrm{m}$. Seventy-two percent of the perimeter consisted of one woven-wire fence $(2.4 \mathrm{~m}$ high), and $28 \%$ consisted of 2 woven-wire fences $(2.4 \mathrm{~m}$ high, separated by $\geq 4 \mathrm{~m})$. Elevation averaged 2,070 $\mathrm{m}$ with the surrounding vegetation characterized by pinyon pine (Pinus edulis), juniper, big sagebrush, and irrigated crops.

\section{Site 7}

The fenced area was 5 ha with a perimeter length of 1,269 $\mathrm{m}$. Eighty-two percent of the perimeter consisted of one woven-wire fence $(2.4 \mathrm{~m}$ high), and $18 \%$ consisted of 2 woven-wire fences $(2.4 \mathrm{~m}$ high, separated by $\geq 4 \mathrm{~m}$ ). Elevation averaged 2,160 $\mathrm{m}$ with the surrounding vegetation characterized by pinyon pine, irrigated crops, and mixed oak.

\section{Site 8}

The fenced area was 3 ha with a perimeter length of $991 \mathrm{~m}$. Eighty-nine percent of the perimeter consisted of one 
woven-wire fence ( $2.4 \mathrm{~m}$ high), and $11 \%$ consisted of 2 woven-wire fences $(2.4 \mathrm{~m}$ high, separated by $\geq 4 \mathrm{~m}$ ). Elevation averaged 2,310 $\mathrm{m}$ with the surrounding vegetation characterized by ponderosa pine, pinyon pine, and mixed oak. Site 8 was within the summer range of elk.

\section{Site 9}

The fenced area was 65 ha with a perimeter length of 5,290 $\mathrm{m}$. The entire perimeter consisted of one woven-wire fence (2.4 $\mathrm{m}$ high). Elevation averaged 2,260 $\mathrm{m}$ with surrounding vegetation characterized by ponderosa pine, mixed oak, and irrigated crops. Site 9 was approximately $1 \mathrm{~km}$ outside the summer range of mule deer.

\section{METHODS}

\section{Data Collection}

We monitored cervid activity along elk farm fences during October 2003 to January 2005. We identified 4 biologically based seasons: winter (1 Dec-31 Mar), spring migration and birthing (1 Apr-30 Jun), summer (1 Jul-31 Aug), and rut and fall migration (1 Sep-30 Nov). We began monitoring sites 5 to 9 in fall 2003 and sites 1 to 4 in winter 2003. Monitoring continued through mid January 2005 at all sites, except 8, which was withdrawn in early fall 2004.

We used animal-activated camera systems for monitoring animal presence and behavior. Camera systems consisted of Stumpcam $^{\mathrm{TM}}$ model 9951 controllers (Stumpcam, Inc., Tyler, TX) and Sony ${ }^{\circledR}$ Handycam DCR-TRV350 camcorders (Sony Corporation, Tokyo, Japan). We mounted cameras on wooden brackets secured to fence posts, approximately $0.5 \mathrm{~m}$ from fences and focused them down fence lines. We aligned cameras so approximately $67 \%$ of the field of view (FOV, where $\mathrm{FOV}=14 \mathrm{~m}$ at $20 \mathrm{~m}$ from camera) was outside the fence, and the remaining 33\% FOV captured footage inside the fence. We programmed all cameras to record for a 2-minute recording interval after activation and then turn off for 2 minutes before reactivation could occur. We used solar panels (Uni-Solar ${ }^{\circledR}$ FLX-11 panels, San Diego, CA) to increase battery life, maximize footage, and minimize site visits.

We employed 3 to 4 cameras per site. We installed cameras in locations where farmed elk were present inside the fence and where tracks and visual observations indicated high levels of cervid activity on both sides of the fence. We spaced most cameras $\geq 95 \mathrm{~m}$ from adjacent cameras (3 exceptions were $44-\mathrm{m}, 67-\mathrm{m}$, and $72-\mathrm{m}$ spacing). We subdivided sites into separate enclosures, so we relocated cameras if farmed elk were moved. We recorded locations of cameras in Universal Transverse Mercator (UTM) coordinates using a Global Positioning System. We collected video tapes approximately once every 2 weeks. For each recording interval, we documented trigger date, trigger start time, type of fence, whether footage was useable (i.e., animals viewed clearly), species, behavior, and number of individuals viewed on both sides of the fence. Behaviors we documented included nose-to-nose contact, touching (nose-to-other body part), sparring, interacting (standing or moving close together on both sides of fence without physical contact), pacing (walking back and forth), passing by (walking in one direction), loitering, and bedding.

We video-monitored 3 types of fence: 2 parallel wovenwire high fences separated by 1-2 m (sites 2 and 5), single woven-wire high fence (sites 2-4, 6-9), and single wovenwire high fence with 3 -strand offset electric fence (sites 1 and 5). We did not monitor double fences separated by $>2 \mathrm{~m}$.

We collected supplemental evidence of wild cervid presence using 244 randomly placed $1 \times 2-\mathrm{m}$ track plots oriented with the long dimension perpendicular to the fence. Number of track plots per site ranged from $12 \mathrm{~m}$ to $70 \mathrm{~m}$, with a mean spacing of $96 \mathrm{~m}(\mathrm{SD}=52 \mathrm{~m})$. We recorded the location of each track plot in UTM coordinates. We surveyed track plots for cervid presence or absence approximately once every 2 weeks during spring, summer, and fall. Plots were cleared of vegetation, raked, and smoothed the day before each survey to optimize track detection and species identification.

\section{Statistical Analyses}

We used species-specific counts of wild cervids recorded within the FOV per recording interval $(C)$ as an index of wild cervid activity along fences. These counts reflected an opportunity for direct contact through fences and for deposition of potentially infected materials (e.g., bodily fluids and excreta) along fences. We coded a binomial response variable indexing potential risk of direct disease transmission $(D)$ based on contact between wild and farmed cervids through fences. We observed 3 types of direct contact through fences: nose-to-nose, touching, and sparring. We classified nose-to-nose and touching as risks of direct transmission ("at-risk direct contact") but not sparring unless nose-to-nose or touching also occurred. We classified touching as an at-risk direct contact because self grooming by CWD-infected cervids might spread infectious prions from saliva across the pelage, and subsequent contact by noninfected cervids via naso-oral tissues could result in exposure to infectious prions. For each usable recording interval when wild cervids were in the FOV, we coded $D=1$ if $\geq 1$ at-risk direct contact occurred, otherwise $D=0$.

We estimated rates of incidence (or occurrence) $I_{C}$ and $I_{D}$ (Stokes et al. 2000, Agresti 2002) for response variables $C$ and $D$, respectively, using generalized linear modeling (McCullagh and Nelder 1989). We used the negative binomial distribution and log-link function in the GENMOD procedure of SAS (SAS Institute, Cary, NC). We included log-transformed time that cameras were functionally available to record cervid activity as the offset variable in all incidence rate models (scaled per 1,000 camera-hr, where 1 camera-hr $=1 \mathrm{hr}$ of monitoring by one camera). Therefore, units for incidence rates were animals per 1,000 camera-hours. We used logistic regression in the GENMOD procedure to estimate the proportion of recording intervals that resulted in $D=1$ when $\geq 1$ wild elk was visible 
$\left(P_{D}\right)$. Alternatively, $P_{D}$ can be interpreted as the probability of detecting $\geq 1$ at-risk direct contact during a 2-minute recording interval, given the presence of wild elk. We also used logistic regression to estimate proportion of track plots per survey when wild mule deer or elk were detected $\left(P_{T}\right)$ to index the extent of spatial presence of cervids around perimeters at particular points in time.

We used information-theoretic methods to estimate weight of evidence for candidate models within analysis sets (Anderson et al. 2001, Burnham and Anderson 2002). We reported the strength of evidence in favor of each model using Akaike weights $\left(w_{i}\right)$, where the $w_{i}$ sum to 1 , and larger values indicate better models given specific alternatives within the set (Burnham and Anderson 2002). Our modeling strategy was to estimate response variables by site (if appropriate) while accounting for any season effects. Candidate model sets included 3 models: site + season, site, and an intercept-only model. The intercept-only model allowed for the possibility that a single mean estimate better represented the data than more complex models. Unless otherwise noted, we reported estimates based on models with the highest $w_{i}$. Post hoc review of our data suggested comparisons among fence types. We evaluated fixed effects of fence type on $I_{D}$ and $P_{D}$ in separate analyses because $>1$ type of fence occurred at individual sites, so fence type replaced site in models. Information from each recording interval within a camera location was associated with only one fence type, enabling spatiotemporal discrimination of fence types for modeling.

We pooled counts of $C$ and $D$ into analysis units larger than individual recording intervals to minimize model convergence and parameter estimability problems associated with empty cells (i.e., count $=0$ ). Nevertheless, we ended up with $\geq 1$ empty site or fence-type cells for several response variables so we removed those cells from analyses (Allison 1999). For modeling $I_{C}$ and $I_{D}$, we used year-season-site cells as units of analysis, within which, we summed variables. For modeling effects of fence-type on $I_{D}$, we used yearseason-site-fence cells as units of analysis. We used individual recording intervals when wild elk were present in the FOV and farmed elk were known to occupy the pen as units of analysis for modeling $P_{D}$. We used track plotsurvey-site cells as units of analysis for $P_{T}$.

We reported point estimates and $95 \%$ confidence intervals for response variables on the natural scale, using backtransformed least-square means (SAS Institute), when these values were estimable. For sites and fence types with no direct contacts, we reported point estimates of $I_{D}=0$ without an upper confidence limit, and for $P_{D}=0$, we estimated "exact" upper $95 \%$ confidence limits of $1-(\alpha /$ $2)^{1 / n}$, where $\alpha=0.05$ and $n=$ site-specific total number of recording intervals where wild elk were present along fence lines (Zar 1999). We reported incidence-rate $(I R)$ ratios (e.g., $I R=I_{C, \text { ell }} / I_{C \text {, mule deer }}$ ), relative risk $(R R)$ of detecting elk in track plots compared with mule deer $\left(R R=P_{T, \text { elk }} /\right.$ $P_{T, \text { mule deer }}$ ), and relative risk of direct contact at single woven-wire fences (W1) compared with single woven-wire plus offset electric fences ( $W E$, where $\left.R R=P_{D, W 1} / P_{D, W E}\right)$. We obtained point estimates and $95 \%$ confidence intervals for $I R$ on the natural scale by exponentiating link-scale contrast estimates (Agresti 2002). We estimated $R R$ and Wald 95\% confidence intervals according to Agresti (2002). Confidence intervals in $R R$ and $I R$ that included 1 implied we could not discern a difference between groups.

We conducted simple linear regression between sitespecific $I_{D}$ and $I_{C}, P_{D}$ and $I_{C}, I_{D}$ and $P_{T}$, and $P_{D}$ and $P_{T}$ with a working hypothesis that higher rates of wild elk at fences (indexed by $I_{C}$ and $P_{T}$ ) would lead to higher rates and probabilities of direct contact (REG procedure, SAS Institute). We reported coefficient of determination and regression parameter $\beta$ (i.e., slope) for explanatory variables $I_{C}$ and $P_{T}$ with $95 \%$ confidence intervals on $\beta$.

\section{RESULTS}

We defined camera monitoring effort as the summation, within and among all cameras per site, of time intervals when cameras were functional and available for recording animal presence. Monitoring effort ranged from 20,063 to 35,405 camera-hours for 8 of 9 sites and 14,716 camerahours for site 8 (total: 213,491 camera-hr). We recorded wild mule deer and elk at fence lines at all study sites. Total site-specific counts ranged from 1 to 477 for mule deer and 8 to 841 for elk. We identified 66 recording intervals where nose-to-nose contact occurred and 11 recording intervals where touching behavior occurred between wild and farmed elk (i.e., $D=1$, range: $2-38$ recording intervals among 6 of 9 sites, with sites 1,2 , and 7 having no recorded direct contacts). We recorded no direct contact of any kind between mule deer and farmed elk, so our modeling of direct-contact data focused on elk.

\section{Incidence Rates of Wild Cervid Counts $\left(I_{C}\right)$}

The highest-ranked $I_{C}$ model structure for mule deer, elk, and mule deer or elk combined, included site, but not season $\left(w_{i}: 0.85,0.92\right.$, and 0.89 , respectively; $\left.n=49\right)$. Incidence rates were generally greater for wild elk than for mule deer $\left(I R=8.14,95 \%\right.$ CI: 3.88-17.12). Site-specific $I_{C}$ for mule deer ranged from 0.05 animals to 15.59 animals per 1,000 camera-hours, and $I_{C}$ for elk ranged from 0.64 animals to 46.90 animals per 1,000 camera-hours (Table 1). Incidence rates of deer or elk combined ranged from 2.37 animals to 47.36 animals per 1,000 camera-hours. Camera locations at site 1 had much greater visitation by deer than at other sites $\left(I_{C}=15.59,95 \%\right.$ CI: $\left.5.53-43.97\right)$. Lack of overlap with confidence intervals for other sites suggests deer activity at site 1 may have been unusually high relative to other sites in our study. Excluding site 1, site-specific $I_{C}$ for mule deer was $<2$ animals per 1,000 camera-hours with an average value $<1$ animals per 1,000 camera-hours.

\section{Proportion of Cervid-Positive Track Plots $\left(P_{T}\right)$}

We omitted site 7 from elk models and sites 2, 6, 7, and 9 from mule deer and elk combined models because we detected no tracks for these species-site combinations during spring, summer, and fall surveys (Table 2). On average, elk 
Table 1. Estimated incidence rates and $95 \%$ confidence intervals of wild mule deer and elk $\left(I_{C}\right.$, animals/1,000 hr of monitoring) at camera locations along perimeter fences of 9 elk farms in Colorado, USA, October 2003 to January 2005. ${ }^{\text {a }}$

\begin{tabular}{|c|c|c|c|c|c|c|}
\hline \multirow[b]{2}{*}{ Site } & \multicolumn{2}{|c|}{ Mule deer } & \multicolumn{2}{|c|}{ Elk } & \multicolumn{2}{|c|}{ Mule deer or elk } \\
\hline & Estimate & CI & Estimate & CI & Estimate & CI \\
\hline 1 & 15.59 & $5.53-43.97$ & 31.40 & $11.81-83.46$ & 44.11 & $18.89-103.01$ \\
\hline 2 & 0.39 & $0.12-1.22$ & 5.19 & $1.94-13.86$ & 5.60 & $2.37-13.22$ \\
\hline 3 & 0.51 & $0.17-1.51$ & 46.90 & $17.80-123.61$ & 47.36 & $20.37-110.14$ \\
\hline 4 & 0.35 & $0.11-1.13$ & 9.01 & $3.40-23.89$ & 9.37 & $4.00-21.94$ \\
\hline 5 & 0.59 & $0.23-1.54$ & 15.67 & $6.46-38.00$ & 16.27 & $7.52-35.20$ \\
\hline 6 & 0.05 & $0.01-0.44$ & 19.75 & $8.10-48.13$ & 19.85 & $9.12-43.18$ \\
\hline 7 & 1.42 & $0.54-3.70$ & 0.64 & $0.16-2.57$ & 2.37 & $0.92-6.11$ \\
\hline 8 & 1.28 & $0.41-3.99$ & 4.12 & $1.44-11.79$ & 5.41 & $2.17-13.47$ \\
\hline 9 & 0.05 & $0.01-0.43$ & 4.49 & $1.82-11.10$ & 4.56 & $2.06-10.09$ \\
\hline
\end{tabular}

${ }^{a}$ Estimates based on generalized linear modeling.

were about equally likely to be detected during track-plot surveys as mule deer $(R R=0.93,95 \% \mathrm{CI}: 0.52-1.64)$, but sites 1 and 6 exhibited distinct differences between species. Site 1 again had greater presence of mule deer than other sites. Mean proportion of track plots per survey where we detected mule deer ranged from 0.02 to 0.35 among sites (site + season model, $w_{i}=0.96, n=151$ ), whereas mean $P_{T}$ ranged from 0.00 to 0.30 for elk (site model: $w_{i}=0.71, n=$ 134). We detected mule deer and elk tracks infrequently in the same track plot during the same survey $\left(\bar{x} P_{T}\right.$ ranged from 0.00 to 0.07 among sites; site + season model, $w_{i}=$ $0.99, n=83)$. The greatest spatial extent of cervid presence was indicated by track plots where we detected either mule deer or elk, where mean $P_{T}$ ranged from 0.07 to 0.46 among sites (site + season model, $w_{i}=0.85, n=151$ ). The proportion of track plots per site where we never detected deer or elk tracks ranged from 0.00 to 0.31 .

\section{Incidence $\left(I_{D}\right)$ and Probability $\left(P_{D}\right)$ of At-Risk Direct Contact}

Model-based point estimates of $I_{D}$ for elk ranged from 0.10 to 1.92 at-risk direct contacts per 1,000 camera-hours among 6 sites where $\Sigma D>0$ (site model: $w_{i}=0.79, n=33$; Fig. 1). Point estimates of 0.0 at-risk direct contacts per 1,000 camera-hours are shown without confidence intervals for sites 1,2 , and 7 .

We obtained 1,903 recording intervals when wild elk were present along fences, but we used only 1,486 of those intervals for modeling $P_{D}$ after removing data for empty cells. The site + season model dominated other candidate models $\left(w_{i}=0.99\right)$. Accounting for season effects on modelbased point estimates, $P_{D}$ ranged from 0.00 to 0.11 including 6 model-based and 3 "exact" estimates (Fig. 2). Poor precision for site 7 was due to small sample size $(n=$ 8). All other sites had reasonably large sample sizes for estimating $P_{D}(n \geq 34)$.

Simple linear regression did not indicate a relationship between $I_{D}$ and $I_{C}\left(r^{2}=0.083 ; \beta=0.012,95 \%\right.$ CI: $-0.023-$ $0.046)$ or between $P_{D}$ and $I_{C}\left(r^{2}=0.001 ; \beta=0.0001,95 \%\right.$ CI: $-0.0023-0.0024)$. Similar regressions substituting $P_{T}$ for $I_{C}$ also yielded little evidence of a relationship between $I_{D}$ and $P_{T}\left(r^{2}=0.320 ; \beta=3.44,95 \%\right.$ CI: $\left.-1.04-7.92\right)$ or between $P_{D}$ and $P_{T}\left(r^{2}=0.069 ; \beta=0.103,95 \%\right.$ CI: $-0.234-0.439)$. The best of these regressions $\left(I_{D}\right.$ and $\left.P_{T}\right)$ does suggest potential for a relationship between level of direct contacts and level of wild elk activity at fences (Fig. 3). Predominantly double fencing at 2 sites may have reduced $I_{D}$, adding variability to the data and degrading the regression. Subsequent regression using sites with predominantly single fences improved the correlation $\left(r^{2}=0.464\right)$ but reduced an already small sample size, and the confidence interval on slope still included $0(\beta=4.12,95 \% \mathrm{CI}$ : $-0.971-9.22)$.

\section{Fence-Type Comparison}

We recorded no direct contacts from camera locations at double woven-wire fences during 14,636 camera-hours at site 2 and 27,473 camera-hours at site 5. Using subsets of the full data set $\left(n=49\right.$ for $I_{D}$ and $n=1,439$ for $P_{D}$ after eliminating camera triggers occurring at double fences), we modeled effects of season and fence type (W1 and $W E$ ). The highest-ranked model for $I_{D}$ included only an intercept $\left(w_{i}\right.$ $=0.73$ ), indicating no clear influence of fence type or season on $I_{D}$. Although the fence model had some support $\left(w_{i}=\right.$ $0.24)$, incidence rates for single woven-wire fence $\left(I_{D}=0.52\right.$ animals/1,000 camera-hr, 95\% CI: 0.26-1.03) and wovenwire plus offset electric fence $\left(I_{D}=0.43\right.$ animals $/ 1,000$ camera-hr, 95\% CI: 0.11-1.76) were essentially equal ( $I R=$ 1.20, 95\% CI: $0.25-5.75)$.

For $P_{D}$, the fence + season model had most support $\left(w_{i}=\right.$ $0.99)$. At-risk direct contact was $>3$ times more likely ( $R R$ $=3.37,95 \%$ CI: $1.51-7.49)$ when wild elk were present at single woven-wire fences $\left(P_{D}=0.059,95 \%\right.$ CI: $0.046-$ $0.075)$ than at similar fences coupled with 3 -strand offset electric fence $\left(P_{D}=0.017,95 \%\right.$ CI: 0.009-0.035; Fig. 4).

\section{DISCUSSION}

Our results confirm the potential for CWD transmission between wild and farmed cervids at fence lines via direct and indirect modes. We documented clear evidence of direct contact between wild and farmed elk through single wovenwire fences. Lack of direct contact between mule deer and elk may have resulted from avoidance of elk by mule deer, which has been documented by others (Johnson et al. 2000, 
Table 2. Mean proportion and $95 \%$ confidence interval of track plots per survey $\left(P_{T}\right)$ containing tracks of wild mule deer or elk along perimeter fences of 9 elk farms in Colorado, USA, October 2003 to January 2005. ${ }^{\mathrm{a}}$

\begin{tabular}{|c|c|c|c|c|c|c|c|c|}
\hline \multirow[b]{2}{*}{ Site } & \multicolumn{2}{|c|}{ Mule deer } & \multicolumn{2}{|c|}{ Elk } & \multicolumn{2}{|c|}{ Mule deer or elk } & \multicolumn{2}{|c|}{ Mule deer and elk } \\
\hline & Estimate & CI & Estimate & CI & Estimate & CI & Estimate & CI \\
\hline 1 & 0.35 & $0.30-0.41$ & 0.18 & $0.13-0.24$ & 0.46 & $0.40-0.53$ & 0.07 & $0.05-0.10$ \\
\hline 2 & 0.06 & $0.03-0.12$ & 0.03 & $0.01-0.13$ & 0.09 & $0.04-0.18$ & 0.00 & $0.00-0.20^{\mathrm{b}}$ \\
\hline 3 & 0.15 & $0.10-0.22$ & 0.30 & $0.21-0.40$ & 0.40 & $0.31-0.50$ & 0.05 & $0.03-0.09$ \\
\hline 4 & 0.02 & $0.01-0.05$ & 0.06 & $0.02-0.12$ & 0.07 & $0.04-0.13$ & $<0.01$ & $0.00-0.03$ \\
\hline 5 & 0.04 & $0.02-0.11$ & 0.10 & $0.04-0.21$ & 0.14 & $0.07-0.25$ & 0.01 & $0.00-0.05$ \\
\hline 6 & 0.02 & $<0.01-0.07$ & 0.22 & $0.13-0.35$ & 0.24 & $0.15-0.36$ & 0.00 & $0.00-0.19^{\mathrm{b}}$ \\
\hline 7 & 0.07 & $0.03-0.15$ & 0.00 & $0.00-0.20^{\mathrm{b}}$ & 0.07 & $0.02-0.18$ & 0.00 & $0.00-0.20^{\mathrm{b}}$ \\
\hline 8 & 0.15 & $0.08-0.28$ & 0.05 & $0.01-0.23$ & 0.19 & $0.09-0.36$ & 0.01 & $<0.01-0.06$ \\
\hline 9 & 0.06 & $0.03-0.10$ & 0.04 & $0.02-0.11$ & 0.10 & $0.06-0.17$ & 0.00 & $0.00-0.21^{\mathrm{b}}$ \\
\hline
\end{tabular}

${ }^{a}$ Track plots not surveyed during winter (1 Dec-31 Mar).

b No tracks of this species group detected during spring, summer, or fall surveys. Upper CI based on "exact" method; all others based on generalized linear modeling.

Stewart et al. 2002, Stephens et al. 2003). Although we commonly recorded wild mule deer along fences, there appears to be little risk of direct transmission of disease between wild mule deer and farmed elk.

Subjectively, direct contact involving wild elk and farmed elk appeared rare per time unit. The maximum site-specific $I_{D}$ we estimated was approximately 2 contacts per 1,000 camera-hours. However, we monitored only a very small proportion of site perimeters $(0.5-3.2 \%)$, and total contacts per time unit were likely higher than our estimates. In contrast, our estimates of $P_{D}$ are likely less biased. The probabilities we estimated seem nontrivial (approx. 11\% at one site) but it is unknown whether such contacts are

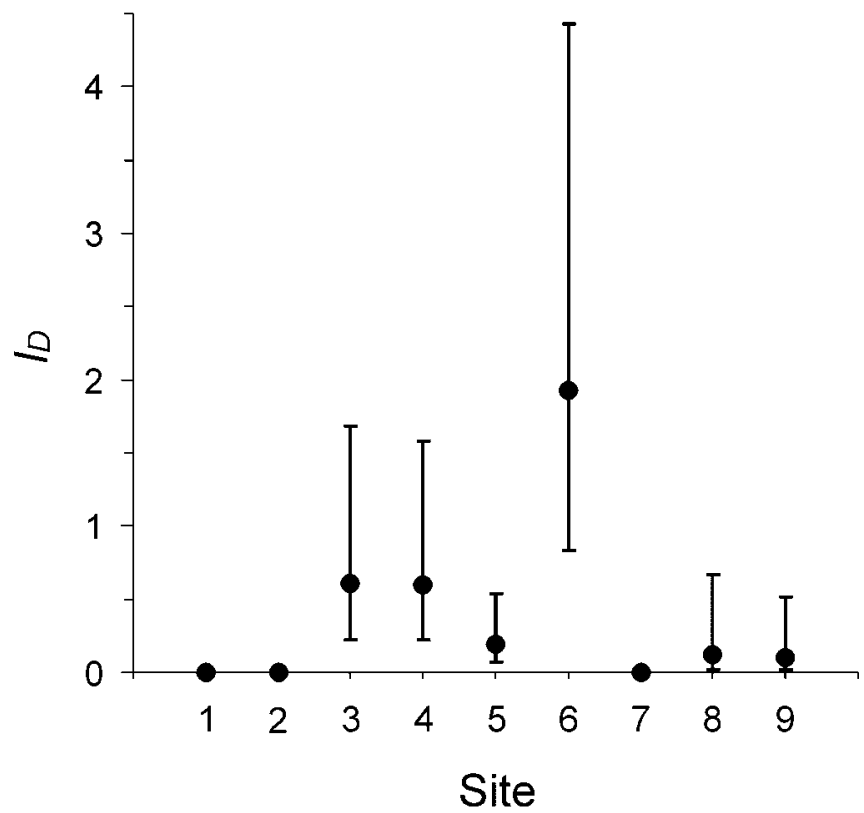

Figure 1. Incidence rate of at-risk direct contacts per 1,000 hours of monitoring $\left(I_{D}\right)$ at camera locations along fence lines at 9 elk farms in Colorado, USA, October 2003 to January 2005. At-risk direct contact included touching between wild and farmed elk involving naso-oral tissues of $\geq 1$ animal. Error bars show model-based $95 \%$ confidence intervals. For sites 1,2 , and 7 , confidence intervals were not estimable using generalized linear modeling because we recorded no direct contacts there. adequate for direct lateral transmission of CWD on a onetime or even repeated basis.

Presence of wild cervids at elk-farm fence lines is significant because CWD appears to be transmissible via environmental contamination (Miller et al. 2004). Risk of indirect transmission of CWD via environmental contamination (deposition of CWD infected bodily fluids or excreta) may be related to activity levels of wild cervids along fences. We observed approximately 8-times-greater incidence rates of wild elk than mule deer at camera sites. Viewed in isolation, our incidence rates may underrepresent potential risk of environmental contamination because mule deer have approximately 3.5-times-greater CWD prevalence rates than wild elk in areas of Colorado known to have

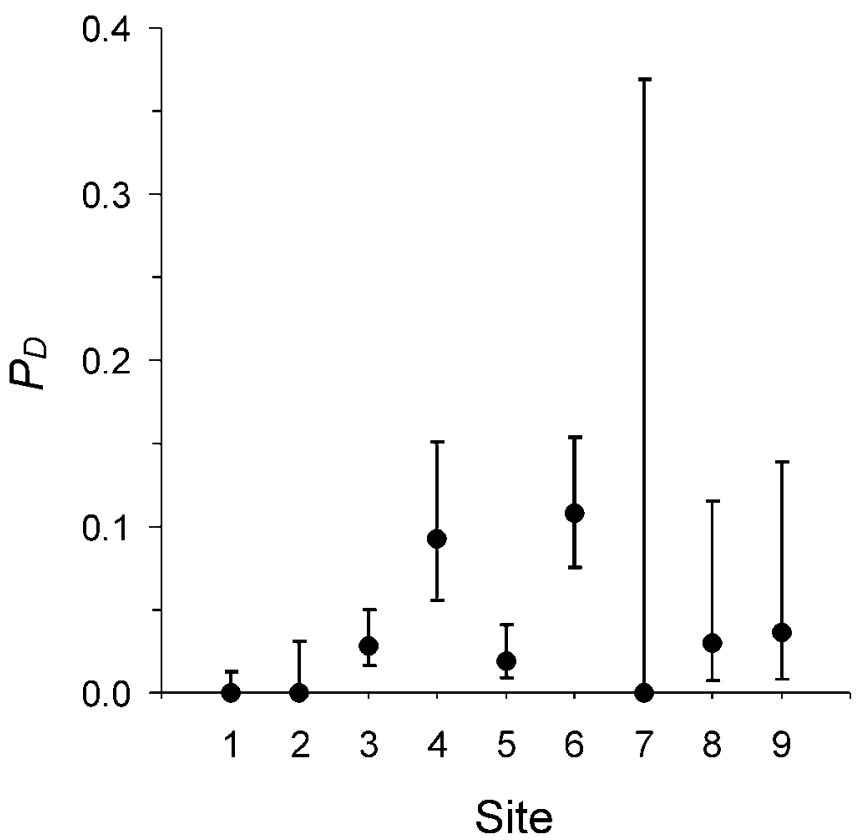

Figure 2. Probability of at-risk direct contact between wild and farmed elk $\left(P_{D}\right)$, given recorded presence of wild elk at camera locations along fences on 9 elk farms in Colorado, USA, October 2003 to January 2005. At-risk direct contact included touching between wild and farmed elk involving naso-oral tissues of $\geq 1$ animal. Error bars show $95 \%$ confidence intervals (model based for sites 3-6, 8, and 9, and exact for 1, 2, and 7). 


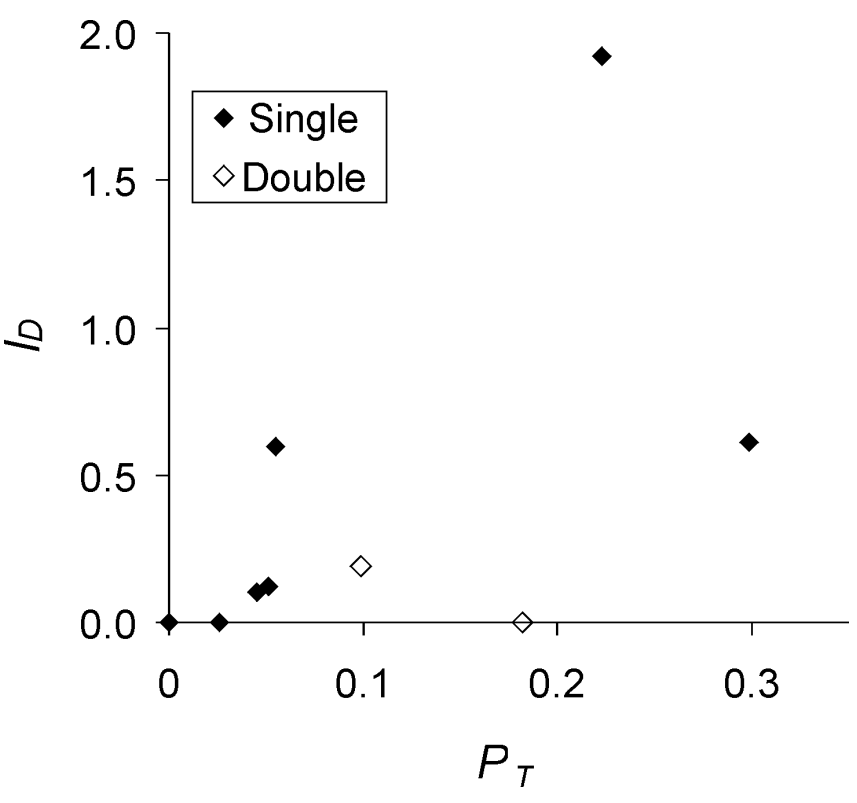

Figure 3. Site-specific estimates of incidence rate of at-risk direct contacts per 1,000 hours of monitoring $\left(I_{D}\right)$ between wild and farmed elk versus proportion of cervid-positive track plots per survey $\left(P_{T}\right)$ along fences on 9 elk farms in Colorado, USA, October 2003 to January 2005. At-risk direct contact included touching between wild and farmed elk involving naso-oral tissues of $\geq 1$ animal. Solid symbols indicate sites with predominantly single woven-wire fences, and open symbols indicate sites with predominantly double fences (including offset electric with woven wire).

CWD (our interpretation of data presented by Miller [2006]). We estimated a maximum site-specific rate of 47 animals per 1,000 camera-hours for deer and elk combined. On average, $\geq 1$ wild elk or mule deer visited approximately $25 \%$ of track plots overnight during the spring to fall seasons. Thus, considerable opportunity appears to exist for deposition of CWD infected excreta on both sides of fences.

Johnson et al. (2006) demonstrated that scrapie prions strongly bound to soil and remained infectious (based on intracerebral inoculation into hamsters). Although they did not demonstrate infectivity of soil-bound prions via oral exposure, they speculated that soil reservoirs might contribute to CWD epizootics. Assuming an infectious reservoir of CWD prions bound to soil particles near fence lines, any process capable of moving soil particles (e.g., wind, runoff, or rodent activities) could move infective prions across fence lines.

Other studies have demonstrated that scrapie prions strongly bind to stainless steel wires and remain infectious via intracerebral contact (Flechsig et al. 2001, Yan et al 2001) or via contact with cultured cells (Weissmann et al. 2002). Mathiason et al. (2006) showed CWD-contaminated saliva to be infectious orally. We occasionally observed elk licking woven-wire fencing. Such behavior, if practiced by CWD-infected cervids, might lead to contamination of fence wire. However, it is not known whether CWD transmission to noninfected cervids could occur from licking contaminated fence wire.

We did not design our study to evaluate fence types but opportunistically compared those that existed at our sites.

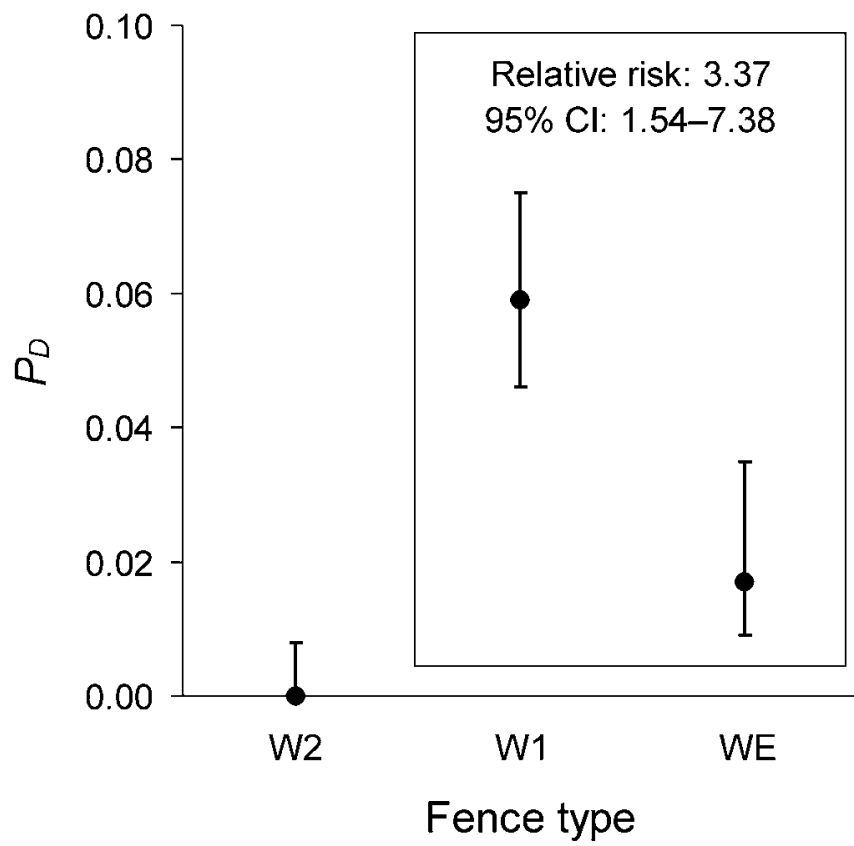

Figure 4. Effect of fence type on probability of at-risk direct contact between wild and farmed elk $\left(P_{D}\right)$, given recorded presence of wild elk at camera locations along fences at 9 elk farms in Colorado, USA, October 2003 to January 2005. At-risk direct contact included touching between wild and farmed elk involving naso-oral tissues of $\geq 1$ animal. Fence types included 2 parallel woven-wire high fences separated by 1-2 $\mathrm{m}$ (W2), single woven-wire high fence (W1), and single woven-wire high fence with 3strand offset electric fence (WE). Error bars show $95 \%$ confidence interval (model based for W1 and WE, and exact for W2 fence types). Odds ratio compared $\mathrm{W} 1$ relative to $\mathrm{WE}$ fence types.

Single woven-wire fence was the dominant type at most of our study sites. Other fence types (W2 and WE) were monitored at only 2 sites each, and one site gradually changed fence type (W1 to W2) during our study. During limited monitoring of W2 fences, we recorded no direct contact.

Based on our analyses, WE fence was not associated with lower $I_{D}$, but was associated with lower $P_{D}$. We did not draw distinction in analyses between the 2 sites that had WE fence, but there were potentially important differences in design and maintenance of fences between sites 1 and 5 . The electric fence was inside the woven-wire fence at site 1 but outside at site 5 . Farmed elk at site 1 were constantly exposed to the electric fence and potentially had more opportunity for aversive conditioning than wild elk at site 5 . The fence at site 1 was of better quality and better maintained than the fence at site 5. All at-risk direct contact we recorded at WE fence occurred at site 5 (8 contacts in 7,932 camera-hr). In contrast, we accumulated 22,701 camera-hours at WE fence at site 1 but recorded no direct contact, despite relatively high occurrence of wild elk $\left(I_{C}=31.4\right.$ animals/1,000 camera-hr; Table 1$)$. However, while servicing cameras at site 1 , we once visually observed 2 bulls sparring through the woven-wire fence and the farmed bull was clearly touching the electric fence. This observation shows how motivation may sometimes overcome the deterrent effect of electric fence. Regardless, it appears possible that a well-designed and well-maintained offset 
electric fence may offer worthwhile levels of deterrence to at-risk direct contact between wild and farmed elk.

We attempted to randomly sample from the population of privately owned elk farms in Colorado, but because not all elk farm operators we contacted were willing to participate in the study, our sample of willing participants may not represent the overall population of elk farms in Colorado. At farms, we selected camera sites subjectively (nonrandomly) to maximize likelihood of detecting wild cervids. Therefore, we cannot reliably extrapolate our estimates to full perimeters.

\section{MANAGEMENT IMPLICATIONS}

Our results suggest infrequent direct contact between wild mule deer and farmed elk through fences at our study sites. Behavior of these groups may impede interspecific direct transmission of CWD through fences, but wild and farmed elk appear to directly interact in ways that could facilitate disease transmission. Wildlife managers and cervid farmers may be able to reduce probability of direct contact between wild and farmed cervids with double woven-wire fences. Further, CWD transmission via indirect routes would likely be reduced through double fencing. Our results are suggestive, but do not provide definitive evidence, that well-built and well-maintained offset electric fence used in conjunction with a single woven-wire high fence might provide a cost-effective alternative to double woven-wire high fence.

\section{ACKNOWLEDGMENTS}

We thank owners of elk farms for granting access to their properties. We also thank T. A. Felix, A. W. Hubble, M. McCollum, M. D. Meier, M. Perkins, M. J. Pipas, S. J. Robinson, and M. P. Schenk for assistance with field work. All procedures were approved by the United States Department of Agriculture, Animal and Plant Health Inspection Service, Wildlife Services, National Wildlife Research Center, Institutional Animal Care and Use Committee. Reference to trade names does not imply United States government endorsement of commercial products or exclusion of similar products with equal or better effectiveness.

\section{LITERATURE CITED}

Agresti, A. 2002. Categorical data analysis. Second edition. John Wiley and Sons, New York, New York, USA.

Allison, P. D. 1999. Logistic regression using SAS: theory and application. SAS Institute, Cary, North Carolina, USA.

Anderson, D. R., W. A. Link, D. H. Johnson, and K. P. Burnham. 2001. Suggestions for presenting the results of data analyses. Journal of Wildlife Management 65:373-378.

Buck, J. M. 2002. Status and management implications of captive cervid farming in the northeast. Transactions of the North American Wildlife and Natural Resources Conference 67:297-307.

Burnham, K. P., and D. R. Anderson. 2002. Model selection and multimodel inference: a practical information-theoretic approach. Second edition. Springer-Verlag, New York, New York, USA.

Colorado Division of Wildlife. 2004. Natural diversity information source. $<$ http://ndis.nrel.colostate.edu/ftp/index.html $>$. Accessed 22 Jun 2005.

Coon, T. G., H. Campa, A. B. Felix, R. B. Peyton, S. R. Winterstein, F.
Lupi, M. Schulz, and J. Sikarskie. 2002. Farming captive cervids: a review of social, economic and ecological opportunities and risks in Michigan and North America. Transactions of the North American Wildlife and Natural Resources Conference 67:251-268.

Demarais, S., R. W. De Young, L. J. Lyon, E. S. Williams, S. J. Williamson, and G. J. Wolf. 2002. Biological and social issues related to confinement of wild ungulates. Wildlife Society Technical Review 02-3. The Wildlife Society, Bethesda, Maryland, USA.

Diez, J. R., M. Gilsdorf, and R. Werge. 2002. The federal role in regulating alternative livestock operations. Transactions of the North American Wildlife and Natural Resources Conference 67:289-296.

Flechsig, E., I. Hegyi, M. Enari, P. Schwarz, J. Collinge, and C. Weissmann. 2001. Transmission of scrapie by steel-surface-bound prions. Molecular Medicine 7:679-684.

Johnson, B. K., J. W. Kern, M. J. Wisdom, S. L. Findholt, and J. G. Kie. 2000. Resource selection and spatial separation of mule deer and elk during spring. Journal of Wildlife Management 64:685-697.

Johnson, C. J., K. E. Phillips, P. T. Schramm, D. McKenzie, J. M. Aiken, and J. A. Pedersen. 2006. Prions adhere to soil minerals and remain infectious. PLoS Pathogens 2:296-302.

Lanka, R. P., and R. J. Guenzel. 1991. Game farms: what are the implications for North American elk? Pages 285-291 in A. G. Christensen, L. J. Lyon, and T. N. Lonner, compilers. Proceedings of the Elk Vulnerability Symposium, Montana State University, Bozeman, USA.

Mathiason, C. K., J. G. Powers, S. J. Dahmes, D. A. Osborn, K. V. Miller, R. J. Warren, G. L. Mason, S. A. Hays, J. Hayes-Klug, D. M. Seelig, M. A. Wild, L. L. Wolfe, T. R. Spraker, M. W. Miller, C. J. Sigurdson, G. C. Telling, and E. A. Hoover. 2006. Infectious prions in the saliva and blood of deer with chronic wasting disease. Science 314:133-136.

McCullagh, P., and J. A. Nelder. 1989. Generalized linear models. Second edition. Chapman and Hall, New York, New York, USA.

Miller, M. W. 2006. Chronic wasting disease in Colorado, 2003-2005. $<$ http://wildlife.state.co.us/NR/rdonlyres/00E03802-49F8-4BD3-8EBA857106D32554/0/CWDreport2003_2005.pdf> Accessed 9 Aug 2006.

Miller, M. W., and E. T. Thorne. 1993. Captive cervids as potential sources of disease for North America's wild cervid populations: avenues, implications and preventative management. Transactions of the North American Wildlife and Natural Resources Conference 58:460-467.

Miller, M. W., M. A. Wild, and E. S. Williams. 1998. Epidemiology of chronic wasting disease in captive Rocky Mountain elk. Journal of Wildlife Diseases 34:532-538.

Miller, M. W., and E. S. Williams. 2003. Horizontal prion transmission in mule deer. Nature 425:35-36.

Miller, M. W., and E. S. Williams. 2004. Chronic wasting disease of cervids. Current Topics in Microbiology and Immunology 284:193-214.

Miller, M. W., E. S. Williams, N. T. Hobbs, and L. L. Wolfe. 2004 June. Environmental sources of prion transmission in mule deer. Emerging Infectious Diseases 10(6). < http://www.cdc.gov/ncidod/EID/vol10no6/ 04-0010.htm>. Accessed 6 Dec 2005.

Miller, M. W., E. S. Williams, C. W. McCarty, T. R. Spraker, T. J. Kreeger, C. T. Larsen, and E. T. Thorne. 2000. Epizootiology of chronic wasting disease in wild cervids in Colorado and Wyoming. Journal of Wildlife Diseases 36:676-690.

Prusiner, S. B. 1998. Prions. Proceedings of the National Academy of Sciences 95:13363-13383.

Sigurdson, C. J., E. S. Williams, M. W. Miller, T. R. Spraker, K. I. O'Rourke, and E. A. Hoover. 1999. Oral transmission and early lymphoid tropism of chronic wasting disease $\mathrm{PrP}^{\mathrm{res}}$ in mule deer fawns (Odocoileus hemionus). Journal of General Virology 80:2757-2764.

Spraker, T. R., R. R. Zink, B. A. Cummings, M. A. Wild, M. W. Miller, and K. I. O'Rourke. 2002. Comparison of histological lesions and immunohistochemical staining of proteinase-resistant prion protein in a naturally occurring spongiform encephalopathy of wild mule deer (Odocoileus hemionus) with those of chronic wasting disease of captive mule deer. Veterinary Pathology 39:110-119.

Stephens, R. M., A. W. Alldredge, and G. E. Phillips. 2003. Aggressive interactions of Rocky Mountain elk, Cervus elaphus nelsoni, during the calving season toward mule deer, Odocoileus hemionus, in central Colorado. The Canadian Field-Naturalist 117:316-317.

Stewart, K. M., R. T. Bowyer, J. G. Kie, N. J. Cimon, and G. K. Johnson. 2002. Temporospatial distributions of elk, mule deer, and cattle: resource 
partitioning and competitive displacement. Journal of Mammalogy 83: 229-244.

Stokes, M. E., C. S. Davis, and G. G. Koch. 2000. Categorical data analysis using the SAS system. Second edition. SAS Institute, Cary, North Carolina, USA.

Weissmann, C., M. Enari, P.-C. Klöhn, D. Rossi, and E. Flechsig. 2002. Transmission of prions. Proceedings of the National Academy of Science 99:16378-16383.

Wheaton, C., M. Pybus, and K. Blakely. 1993. Agency perspectives on private ownership of wildlife in the United States and Canada. Transactions of the North American Wildlife and Natural Resources Conference 58:487-494.

Williams, E. S. 2003. Scrapie and chronic wasting disease. Clinics in Laboratory Medicine 23:139-159.

Williams, E. S. 2005. Chronic wasting disease. Veterinary Pathology 42: 530-549.

Williams, E. S., and M. W. Miller. 2002. Chronic wasting disease in deer and elk in North America. Revue Scientifique et Technique Office International des Epizooties 21:305-316.
Williams, E. S., M. W. Miller, T. J. Kreeger, R. H. Kahn, and E. T. Thorne. 2002. Chronic wasting disease of deer and elk: A review with recommendations for management. Journal of Wildlife Management 66: $551-563$

Williams, E. S., and S. Young. 1980. Chronic wasting disease of captive mule deer: a spongiform encephalopathy. Journal of Wildlife Diseases 16: 89-98.

Williams, E. S., and S. Young. 1982. Spongiform encephalopathy of Rocky Mountain elk. Journal of Wildlife Diseases 18:465-471.

Yan, Z.-X., L. Stitz, P. Heeg, E. Pfaff, and K. Roth. 2001. Infectivity of prion protein bound to stainless steel wires: a model for testing decontamination procedures for transmissible spongiform encephalopathies. Infection Control and Hospital Epidemiology 25:280-283.

Zar, J. H. 1999. Biostatistical analysis. Fourth edition. Prentice-Hall, Upper Saddle River, New Jersey, USA.

Associate Editor: McCorquodale. 